\title{
Research Paper: Effects of Low-Level Laser Versus Laser Acupuncture in Patients With Knee Osteoarthritis: A Randomized Controlled Trial
}

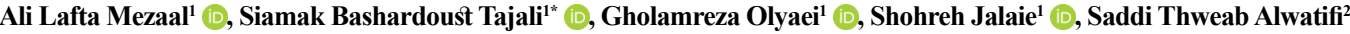

1. Department of Physiotherapy, School of Rehabilitation, Tehran University of Medical Sciences, Tehran, Iran.

2. Higher Diploma of Rheumatology Rehabilitation, Al-Suwaira Hospital, Wasit, Iraq.

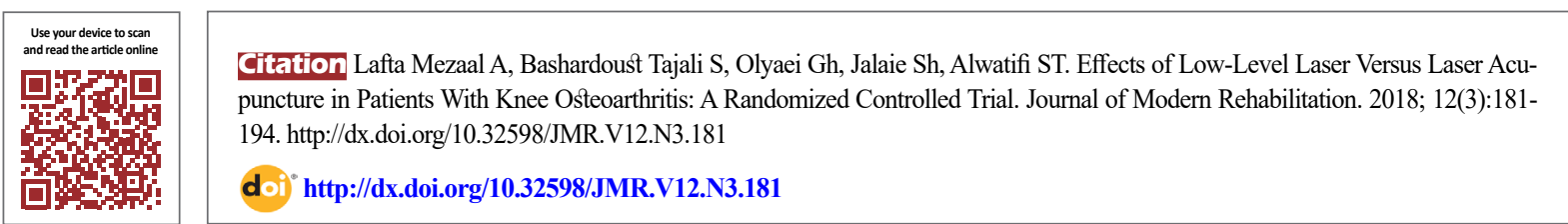

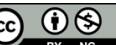

Article info:

Received: 14 Jan 2018

Accepted: 23 May 2018

Available Online: 01 Jul 2018

\begin{abstract}
Introduction: Osteoarthritis (OA) is one of the common causes of disabilities in adults. The prevalence of Knee Osteoarthritis (KOA) is approximately $4.9 \%$ among people over $26,16.7 \%$ among people over 45 , and $12.1 \%$ among people over 60 years old. This study aims to determine the effects of Low-Level Laser Therapy (LLLT) and laser acupuncture in decreasing pain and increasing functional activity in patients with subacute and chronic KOA.

Materials and Methods: In this randomized, single-blind, controlled study, the patients with grades 2 and 3 primary KOA were assigned into two experimental groups (active low-level laser and acupuncture laser) and one control group (infrared \& exercise). The patients in the experimental group I $(\mathrm{n}=23)$ were under low-level Ga-Al-As diode laser, 830-nm continuous waves, and received laser irradiation of $30 \mathrm{~mW} / \mathrm{cm}^{2}$ power density, $3 \mathrm{~mW}$ output power, $0.1 \mathrm{~cm}^{2}$ spot size, with a total dose of $18 \mathrm{~J}$ and for 10 minutes on 6 acupuncture points (SP10, ST34 ST35, GB34, Xiyan, SP9) around the knee in each session. The patients in the experimental group II $(n=23)$ received $3 \mathrm{~J}$ power irradiation in each $\mathrm{cm}^{2}$ in a gridding technique over a triangle-like surface of $15 \mathrm{~cm}^{2}$ over the medial, lateral, and anterior sides of the knee with a total energy density of $45 \mathrm{~J} / 15 \mathrm{~cm}^{2}$ for each session. Laser therapy was applied 5 times per week for a period of two weeks ( 10 sessions in total). The patients in the control group (group III) were under conventional physiotherapy (superficial heat therapy and isometric knee exercises for 15 minutes every day for a similar period ( 10 sessions in 2 weeks). The outcome study measures were pain level at rest rated by Numeric Rating Scale (NRS), Western Ontario and McMaster Universities Osteoarthritis index (WOMAC), and Short Form of McGill Pain Questionnaire (SF-MPQ). In addition, active knee flexion and extension Range of Motions (ROMs) were measured too. These variables were evaluated at the baseline time, before the intervention, and after the intervention, on the final day of the intervention.
\end{abstract}

Results: Based on statistical outcomes, a significant pain reduction by NRS and McGill, an increase in functional activity by WOMAC as well as an increase in the Range of Motion of the knee were observed in three study groups after 10 sessions. However, the result of ANOVA test showed significant difference in pain reduction among three groups and the post hoc Least Significant Difference (LSD) test showed the significant difference between laser acupuncture and conventional laser groups with the control group; the largest improvement was found in Group I. In terms of functional activity, the post hoc LSD test showed the significant difference between conventional laser and laser acupuncture groups with the control group; the largest improvement was found in Group II. No significant difference was observed among the three groups with regard to the mean values of active knee flexion and extension.

Conclusion: Laser acupuncture and conventional laser are more effective in reducing pain and increasing functional activity in patients with KOA compared to conventional treatment. Clinically, laser acupuncture would appear to be superior in pain reduction.

acupuncture, Knee,

Osteoarthritis

* Corresponding Author:

Siamak Bashardoust Tajali, PT. PhD.

Address: Department of Physiotherapy, School of Rehabilitation, Tehran University of Medical Sciences, Tehran, Iran.

Tel: +98 (21) 77685105

E-mail:s_bashardoust@sina.tums.ac.ir 


\section{Introduction}

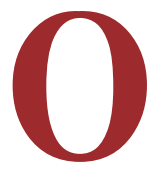

steoarthritis (OA) is a degenerative disease characterized by progressive loss of articular cartilage combined with subchondral sclerosis, joint space narrowing, marginal osteophytes, subchondral cysts, and finally joint deformation. Osteoarthritis may clinically present by pain, restricted Range of Motion, and muscle weakness [1]. These problems can cause difficulties in daily living activities and impaired quality of life $[2,3]$. Based on data collected from several large population-based studies, it is estimated that approximately $12 \%$ of the western countries' population or 27 million adults aged 25 or older have clinical OA of some joints [4]. It is the most common form of arthritis and extremely prevalent among individuals older than 40 years [5].

The age-related changes in muscle strength and Knee OA (KOA) increase susceptibility to falls, which are associated with significant morbidity and mortality in the elderly [6]. No definite factor that predisposes an individual to OA has yet been identified, but aging is strongly associated with OA [7]. Genetic factors account for $39 \%$ to $65 \%$ of radiographic OA of the hand, hip, and knee in women and as much as $70 \%$ of OA cases of the spine [8]. Repetitive microtrauma in the etiology of OA has also been mentioned [7]. Finally, obesity has been shown to be a risk factor for the development of OA in old age, most evident in the knee joint and to a lesser extent in the hip and hands [9].

Medical therapies generally focus on pain and inflammation reduction. Early aggressive pharmacological therapy is associated with prevention of joint damage and preservation of long-term function. The major classifications of drugs used in Rheumatoid Arthritis (RA) management include Nonsteroidal Anti-Inflammatory Drugs (NSAIDs) and Disease-Modifying Antirheumatic Drugs (DMARDs), which include the Biological Response Modifiers (BRMs) and corticosteroids. However, $2 \%$ to $4 \%$ of the patients experience serious adverse effects, including gastrointestinal bleeding, ulcers, and perforation [10]. Subsequently, nonpharmacological treatments must be prioritized as first-line therapy, especially in older adults. Some non-pharmacological methods are exercise [11], heat [12], cold [13], ultrasonic therapy [14], electromagnetic therapy [15], transcutaneous electrical nerve stimulation [16], orthoses [17], patellar taping [18], acupuncture [19], patients' education [20], and Low-Level Laser Therapy (LLLT) [21].
LLLT has the potential physiologic and therapeutic effects for the OA care, since absorption of light energy by the chromophores (i.e. mitochondrial cytochromes) is presumed to trigger the photobiomodulation effects such as analgesia, anti-inflammation, and increase in protein and collagen synthesis, which enhance cellular metabolism and promote function and soft-tissue healing [22]. The effect of the LLLT on the KOA is related to the number of affected points, laser wavelength, energy density, continuous or pulse mode application, treatment duration, the method of application, number of sessions, follow-up, the severity of the OA, and surface of application [23].

The effects of these factors should be investigated on the LLLT effectiveness for the OA in randomized controlled clinical trials [24]. The previous randomized controlled trial just used Visual Analog Scale (VAS) for assessing pain and their results were very different [25].

Tascioglu et al. [26] used Gal-Al-As diode laser device with $830 \mathrm{~nm}$ wavelength, two treatment groups with dosage $3 \mathrm{~J}$ per point and $1.5 \mathrm{~J}$ per point, respectively. The laser therapy was done 5 times per week with 10 sessions in total. They suggested that LLLT has no effect on pain in patients with KOA. There were no significant differences between the two groups based on performance improvement, pain relief, and other clinical outcomes [26, 27]. Results of Huang and colleagues [28] meta-analysis on 612 studies and 9 RCTs with a total 518 patients show that the Standardized Mean Difference (SMD) in Visual Analog Scale (VAS) pain score Right After the Therapy (RAT) and then 2 weeks after the therapy was not significantly different between LLLT and control (SMD=-0.28 $[95 \% \mathrm{CI}=-0.66,0.10], \mathrm{I}^{2}=66 \%$ ).

There were no substantial differences regarding VAS pain score following low-level laser application in patients with Osteoarthritis during a period of 12 weeks follow-up. Similarly, there was no evidence of LLLT effectiveness based on Western Ontario and McMaster Universities Arthritis Index (WOMAC) pain, stiffness or function outcomes (5 and 3 studies had outcome data right after therapy and 12 weeks after therapy, respectively). But Rayegani and colleagues [23] analysis reports a significant pain reduction in patients who received the LLLT. The efficacy of the LLLT in the KOA patients has remained unknown due to these conflicting results.

Different types of electrophysical appliances are applied to trigger the acupuncture points to relieve pain. One of these tools is low-level lasers [29, 30]. A different 
technique in the acupuncture field is the laser acupuncture which is a non-intensive technique. Yet it is more than just the summation of two different forms of therapy. What makes laser acupuncture so interesting is the synergy that exponentially increases the effects of both acupuncture and phototherapy [31]. There are several review articles concerning clinical effectiveness of laser acupuncture [31]. However, few published studies have investigated the efficacy of laser acupuncture on KOA and their reports are contradictory [32-36].

The rationale of this study is to compare the effects of LLLT with two other methods of application (gridding technique and laser acupuncture technique) and measuring the multiple dimensions of acute and chronic pain. The McGill Pain Questionnaire (MPQ) is a reliable and valid generic pain measurement tool. It is a perfect tool for the research purposes to describe quantity (intensity) and quality of pain in patients with Knee Osteoarthritis [25].

\section{Materials and Methods}

This study was designed as a single-blind randomized clinical trial and conducted at the Department of Rehabilitation in Al-Suwaira Hospital, Wasit Governorate, Iraq between April 2018 and December 2018. All the procedures were carried out after the study was approved by the Scientific Board and Ethics Committee of the School of Rehabilitation, Tehran University of Medical Science (IR.TUMS.FNM.REC1397.161). All participants were informed about the procedures that would be carried out. The participants who agreed voluntarily to sign an identified consent form were considered for the study.

\section{Study patients}

The patients from both genders aged between 35 and 70 years with a Mean \pm SD age of $56.65 \pm 8.568$ years were recruited for the study. They were randomly assigned into three groups; laser acupuncture $(n=23)$, conventional laser $(\mathrm{n}=23)$, and conventional physiotherapy $(n=23)$. The participants who met the inclusion criteria were enrolled in this study, including: 1 . Grade II or III of KOA according to the Kellgren and Lawrence grading system [37]; 2. Minimum score of 25 or more based on the Western Ontario McMaster Universities Osteoarthritis index (WOMAC); 3. Knee pain score equal to 4 or more for the last month based on the Numeric Pain Rating Scale (NPRS); and 4. The ability to participate in the study and follow the treatment schedule. The exclusion criteria were having the history of any knee op- eration, history of any hormonal, metabolic, systemic or rheumatologic problems leading to secondary KOA, history of using oral analgesic or NSAIDs in the previous 4 weeks. Moreover, patients would also be excluded from the study if they had a history of malignancy, mental retardation, neurologic dysfunction, having a heart pacemaker, diabetes mellitus, uncontrolled hypertension, or morbid obesity (BMI $\geq 40)$.

The patients were randomly assigned into laser acupuncture group, conventional laser group, and conventional physiotherapy group. Simple random sampling was performed using sealed, randomly filled envelopes describing the treatment groups. The patients did not have any idea that they were in a conventional laser group or laser acupuncture group since the laser device was similar in both groups. Besides, the statistical analyzer did not have any idea about the type of intervention provided for each group. Based on previous studies, a significant difference improvement in the NPRS was

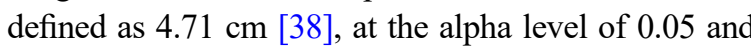
power of 0.8 resulted in an estimated sample size of 23 [39], so a total of 69 patients were recruited for the three study groups.

\section{Study intervention}

The study was conducted for 2 weeks in 10 sessions, 5 sessions per week. The participants were assessed before the treatment (at the baseline) and after the treatment. The assessor asked the patients to lie in the supine position and flex the affected knee $20^{\circ}$ supporting with some pillows. Treatments were performed at the same location and under similar conditions for both laser groups using similar laser device (low-level gallium-aluminumarsenide laser of $810 \mathrm{~nm}$, Lasermed 4098 Carci, Brazil). In group I, each patient received acupuncture LLLT with a dosage of $3 \mathrm{~J}$ on all six points around the knee. These points were identified from the reference acupuncture book (six points were around the knee joint medially and laterally, including SP10, ST34, ST35, GB34, Xiyan, SP9) [40].

All these points are outside of the area that will be treated by the gridding technique. Laser therapy would be provided 5 times per week for a period of 2 weeks. The output power of laser producer was $30 \mathrm{~mW}$ and laser irradiation was applied in a continuous mode of $830 \mathrm{~nm}$ wavelength. Each point received energy of $3 \mathrm{~J}$ per point for $100 \mathrm{~s}$, with a total dosage of $18 \mathrm{~J}$ in each session. In group II, each patient received gridding technique LLLT over $15 \mathrm{~cm}^{2}$ triangle-like on the medial, lateral, and anterior knee gap and each $\mathrm{cm}^{2}$ received $3 \mathrm{~J}$ for 
$100 \mathrm{~s}$, for a total dosage of $45 \mathrm{~J} / 15 \mathrm{~cm}^{2}$. In group III, the patients received heat therapy (infrared lamp of $150 \mathrm{~W}$ ) for 15 minutes and isometric knee isometric exercises (quadriceps setting exercise).

In the isometric quadriceps exercise, the patients lay in a supine position. A rolled-up towel was put beneath the knee and isometric exercise was performed 10 times per set for three sets with 2-min rest between each set. The patients maintained each contraction for $10 \mathrm{~s}$ focusing on the quadriceps muscle contraction [41]. All participants and practitioner wore safety goggles during the procedure.

\section{Clinical outcome measurements}

The same practitioner gave instructions to the patients for the questionnaires and performed outcome measures and collected initial data, including age, weight, height, duration of knee OA and level of pain. If the patients demonstrated symptoms on both knees or when symptoms were similar bilaterally, the dominant painful knee was chosen. The primary outcome measurement was the pain intensity by NPRS and McGill Pain Questionnaire, while WOMAC was used for measuring functional activity with its subscales (pain, stiffness, and function). All outcome measurements were taken at baseline and after the intervention ( 2 weeks).

\section{Pain assessment}

Numeric Pain Rating Scale (NPRS) is an 11-point numeric scale ranges from 0 representing no pain to 10 representing the extreme pain [25] (Appendix 1). The patients were tested with a translated Arabic version of NPR scale, with "no pain" on the left side and "worst pain" on the right side of the line. The patients pinpointed their current level of pain intensity in the knee and marked this with a symbol like $\mathrm{X}$ on the 11-point line. Then, the practitioner registers this number.

Short-form McGill Pain Questionnaire (SF-MPQ) is a shorter version of the original MPQ, and was prepared in 1987 [42] (Appendix 2). The SF-MPQ rating index has 2 subscales 1 . Sensory with 11 words; and 2 . Affective with 4 words extracting from original MPQ. These words or items are rated on an intensity scale from 0 to $3 \mathrm{dem}-$ onstrating none, mild, moderate and severe levels of pain, respectively. There is also one item for present pain intensity and one item for 10 points numeric rating for average pain. In this study, the Arabic version of SF-MPQ was used because the respondents were Arabs [42].

\section{Functional activity assessment}

Western Ontario and McMaster Universities Osteoarthritis index (WOMAC) [43] questions are scored on a basis of 4-point scale, demonstrating from none (0) to mild (1), moderate (2), severe (3), and extreme (4) (Appendix 3). The scores of each subscale are summed up with possible scores of pain from 0 to 20, stiffness from 0 to 8 , and physical function from 0 to 68 . The sum of all three subscales is commonly considered as a total WOMAC score. The Arabic version of WOMAC is approved to be reliable and valid in patients with KOA [44].

\section{Active knee Range of Motion}

Active extension knee Range of Motion was measured with electronic stainless-steel digital angle ruler (Wenzhou Sanhe Measuring Instrument Co., Ltd. China Mainland Zhejiang). It is a valid and reliable measurement tool. In maximal knee extension measurement, the patient is positioned supine with the hip of the tested leg in 90 degrees of flexion. The contralateral leg stays flat on the examination table. The patient extends the knee and tries to reach a maximally tolerable stretch of hamstring muscle as indicated by the practitioner, while the ipsilateral hip remains in 90 degrees of flexion. The knee angle is then measured. The axis of the ruler should be placed at the lateral epicondyle of the femur. The moving arm should point towards the lateral malleolus and the stationary arm towards the greater trochanter [45].

Active flexion knee Range of Motion was measured with electronic stainless-steel digital angle ruler. It is a valid and reliable measurement tool. It was evaluated in a prone lying position, with the extended knee. The patient was asked to bring the heel of the tested leg as close as possible to the buttock while the other foot remained in contact with the plinth. The fulcrum of the goniometry is placed on the lateral epicondyle of the femur of the tested knee with one arm in line with the lateral malleolus and the other arm in line with the greater trochanter [45]

\section{Statistical analysis}

The collected data were statistically analyzed in SPSS (version 20.0). After checking the assumptions, the paired t-test was used to determine the significant improvements within each group. Analysis of Variance (ANOVA) was used to detect the significant differences among the three groups after physical therapy interventions. The Least Significant Difference (LSD) test was used to determine any group that had the best significant 
improvements. The Independent $t$ test was used to determine the difference among groups based on the KOA grades (Kellgren and Lawrence grade scale) for improvements. The correlation test was used to find any correlation between the improvements. $\mathrm{P}<0.05$ was considered statistically significant at $95 \%$ confidence interval.

\section{Results}

A total number of 69 patients (21 [30.4\%] men and 48 [69.6\%] women) completed this study. Their Mean \pm SD age was $55.12 \pm 8.357$ years. All patients had KOA; 45 $(65.2 \%)$ in the right and $24(34.8 \%)$ in left knee. Fortyfour $(63.8 \%)$ patients had grade II and 25 (36.2\%) patients had grade III of KOA. The baseline demographic and clinical characteristics of patients in the three groups were similar with no statistically significant differences (Table 1).

\section{Pain intensity}

\section{McGill Pain Questionnaire}

According to Table 2, after applying the intervention in patients with KOA, significant differences were observed between all scores of McGill parameters $(\mathrm{P}<0.05)$.

\section{Numeric Pain Rating Scale}

As Table 3 indicates, the numeric pain rating scale showed a statistically significant improvement for all study groups after 10 sessions of treatment $(\mathrm{P} \leq 0.001)$. Just one case in group three showed no improvement.

Table 1. Baseline characteristics of study groups

\begin{tabular}{|c|c|c|c|c|}
\hline \multicolumn{2}{|l|}{ Characteristics } & \multirow{2}{*}{$\begin{array}{c}\begin{array}{c}\text { Laser Acupuncture } \\
\text { Group ( } n=23)\end{array} \\
56.65 \pm 8.568\end{array}$} & \multirow{2}{*}{$\begin{array}{c}\begin{array}{c}\text { Conventional } \\
\text { Laser Group } \\
(\mathbf{n}=\mathbf{2 3})\end{array} \\
57.30 \pm 6.852\end{array}$} & \multirow{2}{*}{$\begin{array}{c}\begin{array}{c}\text { Conventional Physiotherapy } \\
\text { Group }(\mathbf{n}=\mathbf{2 3})\end{array} \\
51.39 \pm 8.574\end{array}$} \\
\hline Age (y) & Mean $\pm S D$ & & & \\
\hline \multirow{2}{*}{ Gender ( $n$ ) } & Male & 5 & 6 & 10 \\
\hline & Female & 18 & 17 & 13 \\
\hline Body Mass Index $\left(\mathrm{kg} / \mathrm{m}^{2}\right)$ & Mean $\pm S D$ & $30.81 \pm 4.934$ & $28.66 \pm 4.111$ & $29.43 \pm 3.445$ \\
\hline \multirow{2}{*}{$\begin{array}{l}\text { The degree of Knee } \\
\text { Osteoarthritis }\end{array}$} & Grade II & 13 & 16 & 15 \\
\hline & Grade III & 10 & 7 & 8 \\
\hline WOMAC Osteoarthritis Index & Mean $\pm S D$ & $49.35 \pm 12.375$ & $50.30 \pm 13.858$ & $42.52 \pm 11.413$ \\
\hline McGill Pain Questionnaire & Mean $\pm S D$ & $32.3478 \pm 7.15801$ & $31.5652 \pm 7.91906$ & $32.9130 \pm 7.93103$ \\
\hline Numeric Pain Rating Scale & Mean $\pm S D$ & $7.1304 \pm 1.39167$ & $7.2174 \pm 1.38027$ & $6.7609 \pm 0.92772$ \\
\hline Active Knee flexion (degree) & Mean $\pm S D$ & $110 \pm 10.57871$ & $115.6 \pm 7.63210$ & $111 \pm 11.45139$ \\
\hline Active Knee extension (degree) & Mean $\pm S D$ & $-2.48 \pm 3.217$ & $-1.70 \pm 1.917$ & $-2.09 \pm 2.314$ \\
\hline
\end{tabular}

Table 2. Results and statistical comparisons of the pre-treatment and post-treatment (second weeks) scores of McGill questionnaire in groups I, II, and III

\begin{tabular}{|c|c|c|c|c|c|}
\hline \multirow{2}{*}{\multicolumn{2}{|c|}{ Before Treatment }} & \multicolumn{2}{|c|}{ After Treatment } & \multirow{2}{*}{$95 \% \mathrm{Cl}$ of the Difference } & \multirow{2}{*}{$\mathbf{P}$} \\
\hline & & Mean $\pm S D$ & Mean $\pm S D$ & & \\
\hline \multirow{3}{*}{ McGill } & G1 & $32.3478 \pm 7.15801$ & $12.2174 \pm 4.89858$ & (23.93241) to (16.32846) & $<0.001$ \\
\hline & $\mathrm{G} 2$ & $31.5652 \pm 7.91906$ & $12.0000 \pm 3.43776$ & (22.06241) to (17.06802) & $<0.001$ \\
\hline & G3 & $32.9130 \pm 7.93103$ & $30.4348 \pm 7.48226$ & (1.99269) to (2.96383) & $<0.001$ \\
\hline
\end{tabular}


Table 3. Results and statistical comparisons of the pre-treatment, post-treatment ( 2 weeks) scores of numeric pain rating scale in groups I, I, and III

\begin{tabular}{|c|c|c|c|c|c|c|}
\hline Group & \multicolumn{2}{|c|}{ Median } & \multicolumn{2}{|c|}{ Ranks } & \multirow[t]{2}{*}{$\mathbf{Z}$} & \multirow[t]{2}{*}{$\mathbf{P}$} \\
\hline \multirow{4}{*}{$\mathrm{GI}$} & Before & 7.00 & Positive & 23 & & \\
\hline & \multirow{3}{*}{ After } & \multirow{3}{*}{3.00} & Negative & 00 & -4.258 & $<0.001$ \\
\hline & & & & & & \\
\hline & & & Ties & 00 & & \\
\hline \multirow{4}{*}{ GII } & Before & 7.00 & Positive & 23 & & \\
\hline & \multirow{3}{*}{ After } & \multirow{3}{*}{4.00} & Negative & 00 & -4.272 & $<0.001$ \\
\hline & & & & & & \\
\hline & & & Ties & 00 & & \\
\hline \multirow{4}{*}{ GIII } & Before & 7.00 & Positive & 22 & & \\
\hline & \multirow{3}{*}{ After } & \multirow{3}{*}{5.00} & Negative & 00 & -4.203 & $<0.001$ \\
\hline & & & & & & \\
\hline & & & Ties & 1 & & \\
\hline
\end{tabular}

\section{WOMAC Osteoarthritis Index}

Based on Table 4, the WOMAC Osteoarthritis Index showed a statistically significant improvement for the laser acupuncture group after 10 sessions of treatment $(\mathrm{P}<0.05)$. Also, the mean rank test results of all cases in conventional laser show that it had positive effects $(\mathrm{P}=<0.001)$. In the third group, the results showed a statistically significant improvement after 10 sessions of treatment $(\mathrm{P}=0.00)$, except for two cases.

\section{Active flexion Range of Motion}

Table 5 Wilcoxon signed-ranks test results indicate a significant improvement $(\mathrm{P}=0.003)$. The ranks show that 11 cases in the acupuncture laser group had positive results in active flexion ROM for knee and 12 cases had no change. According to Table 6, significant differences are observed after the treatment in the second group $(\mathrm{P}=0.008)$, and the third group (conventional physiotherapy) $(\mathrm{P}=0.006)$.

Table 4. Results and statistical comparisons of the pre-treatment, post-treatment (second week) WOMAC Osteoarthritis Index in groups I, II, and III

\begin{tabular}{|c|c|c|c|c|c|c|}
\hline Group & \multicolumn{2}{|c|}{ Median } & \multicolumn{2}{|c|}{ Ranks } & \multirow[t]{2}{*}{ Z } & \multirow[t]{2}{*}{$\mathbf{P}$} \\
\hline \multirow{3}{*}{ GI } & After & 19.00 & Positive & 23 & & \\
\hline & \multirow[b]{2}{*}{ Before } & \multirow[b]{2}{*}{53.00} & Negative & 00 & -4.198 & $<0.001$ \\
\hline & & & & 00 & & \\
\hline \multirow{4}{*}{ G II } & After & 13.00 & Positive & 23 & & \\
\hline & \multirow{3}{*}{ Before } & \multirow{3}{*}{52.00} & Negative & 00 & -4.199 & $<0.001$ \\
\hline & & & & & & \\
\hline & & & Ties & 00 & & \\
\hline \multirow{4}{*}{ G III } & After & 37 & Positive & 21 & & \\
\hline & \multirow{3}{*}{ Before } & \multirow{3}{*}{40} & Negative & 00 & -4.072 & $<0.001$ \\
\hline & & & & & & \\
\hline & & & Ties & 2 & & \\
\hline
\end{tabular}


Table 5. Results and statistical comparisons of the pre-treatment, post-treatment (second week) of active flexion Range of Motion in group I

\begin{tabular}{|c|c|c|c|c|c|c|c|}
\hline \multicolumn{2}{|c|}{ Assessment } & \multirow{2}{*}{$\begin{array}{c}\text { Median } \\
110\end{array}$} & \multicolumn{2}{|c|}{ Ranks } & \multirow{2}{*}{$\begin{array}{c}\text { Mean Rank } \\
6\end{array}$} & \multirow[t]{2}{*}{ z } & \multirow[t]{2}{*}{$\mathbf{P}$} \\
\hline & Pre-treatment & & Positive & 11 & & & \\
\hline \multirow[t]{2}{*}{ GI } & & & Negative & 0 & 0 & -2.966 & 0.003 \\
\hline & Post-treatment & 115 & Ties & 12 & & & \\
\hline
\end{tabular}

$J \mathrm{MR}$

Table 6. Results and statistical comparisons of the pre-treatment, post-treatment (second week) of active flexion Range of Motion in groups II and III

\begin{tabular}{ccccc}
\hline \multirow{2}{*}{ Group } & Before Treatment & \multicolumn{2}{c}{ After Treatment } \\
\cline { 2 - 5 } & Mean \pm SD & Mean \pm SD & 95\% Cl of the Difference & P \\
\hline \multirow{2}{*}{ GII } & $115.6087 \pm 7.63210$ & $119.0000 \pm 6.22312$ & $5.79453-0.98808$ & 0.008 \\
GIII & $111.0435 \pm 11.45139$ & $112.3913 \pm 11.44449$ & $2.25686-0.43879$ & 0.006 \\
\hline
\end{tabular}

$J \mathrm{MR}$

Active extension Range of Motion

The result of Table 7 shows that acupuncture laser group has significant effectiveness $(\mathrm{P}=0.024)$, in group of acupuncture laser it has significant effectiveness $(\mathrm{P}=0.024)$ and conventional physiotherapy group it has significant effects in active flexion ROM for knee $(\mathrm{P}=0.016), 12$ cases without any change and 1 case with negative effectiveness.
Table 8 shows the improvement in all parameters of the studied groups. The results show a significant difference in WOMAC, McGill, and NPR scale. With regard to WOMAC improvement, the post hoc test by using adjusted P in Mann-Whitney shows that the significant difference is related to the groups of laser acupuncture with conventional physiotherapy and conventional laser with conventional physiotherapy therapy $(\mathrm{P}=0.000)$. With regard to McGill improvement, the post hoc test by using adjusted $\mathrm{P}$ in Mann-Whitney shows that the significant difference is related to the groups of laser acupuncture

Table 7. Results and statistical comparisons of the pre-treatment, post-treatment (second week) of active extension Range of Motion in groups I, II, and III

\begin{tabular}{|c|c|c|c|c|c|c|}
\hline Groups & \multicolumn{2}{|c|}{ Median } & \multicolumn{2}{|c|}{ Ranks } & z & $\mathbf{P}$ \\
\hline \multirow{3}{*}{ GI } & Before & 0.00 & Positive & 6 & & \\
\hline & \multirow[b]{2}{*}{ After } & \multirow[b]{2}{*}{0.00} & Negative & 0 & -2.226 & 0.026 \\
\hline & & & Ties & 17 & & \\
\hline \multirow{3}{*}{ GII } & Before & 0.00 & Positive & 6 & & \\
\hline & \multirow{2}{*}{ After } & \multirow{2}{*}{0.00} & Negative & 0 & -2.264 & 0.024 \\
\hline & & & Ties & 17 & & \\
\hline \multirow{3}{*}{ GIII } & Before & 0.00 & Positive & 10 & & \\
\hline & \multirow{2}{*}{ After } & \multirow{2}{*}{-2.00} & Negative & 1 & -2.404 & 0.016 \\
\hline & & & Ties & 12 & & \\
\hline
\end{tabular}


Table 8. Comparison for improvement in mean and median parameters for studied groups with Kruskal-Wallis $\mathrm{H}$ test

\begin{tabular}{|c|c|c|c|c|c|}
\hline \multirow{2}{*}{ Outcome Measurement } & \multicolumn{3}{|c|}{ Mean $\pm S D$} & \multirow{2}{*}{$x^{2}$} & \multirow{2}{*}{$\mathbf{P}$} \\
\hline & Group I & Group II & Group III & & \\
\hline WOMAC improvement & $29.78 \pm 13.79$ & $32.39 \pm 12.8$ & $2.6087 \pm 1.19$ & 45.707 & $<0.001$ \\
\hline McGill improvement & $20.13 \pm 8.79$ & $19.56 \pm 5.77$ & $2.4783 \pm 1.12$ & 45.532 & $<0.001$ \\
\hline NPRS improvement & $3.95 \pm 1.364$ & $3.82 \pm 1.26$ & $1.7391 \pm 0.76$ & 35.935 & $<0.001$ \\
\hline Flexion improvement & $3.737 \pm 2.82$ & $5.55 \pm 3.39$ & $2.10 \pm 1.3478$ & 1.594 & 0.451 \\
\hline Extension improvement & $1.475 \pm 0.7826$ & $1.38 \pm 0.7826$ & $1.21 \pm 0.7391$ & 0.342 & 0.843 \\
\hline
\end{tabular}

with conventional physiotherapy and conventional laser with conventional physiotherapy $(\mathrm{P} \leq 0.001)$.

With regard to NPRS improvement, the post hoc test by using adjusted $\mathrm{P}$ in Mann-Whitney shows that the significant difference is related to the groups of laser acupuncture with conventional physiotherapy and conventional laser with conventional physiotherapy $(\mathrm{P} \leq 0.001)$. Kruskal-Wallis $\mathrm{H}$ test showed a non-significant difference in mean values of active knee flexion and extension improvement among the three groups $(\mathrm{P}>0.05)$ (Figure 1).

\section{Discussion}

Osteoarthritis (OA) of the knee joint is a major cause of pain and locomotor disability all over the world. This is the first clinical study to compare the effects of LowLevel Laser Therapy versus laser acupuncture in patients with Knee Osteoarthritis. Based on our study results, the application of Low-Level Laser Therapy (LLLT) or laser acupuncture has a beneficial effect on reducing pain intensity and improving functional outcome in patients with KOA compared to the conventional physiotherapy. However, we did not find any significant differences in the Range of Motion between laser groups and conventional physiotherapy group.

The dose of $3 \mathrm{~J}$ that was used in this study was recommended by WALT for KOA [26]. The intervention was performed in five sessions per week for 2 weeks. Our study showed a statistically significant difference in WOMAC improvement between the LLLT and the control group $(\mathrm{P} \leq 0.001)$ also between the laser acupuncture and the control group $(\mathrm{P} \leq 0.001)$. Regarding the pain intensity, McGill and NRP scale showed improvement in the LLLT group compared with the control group $(\mathrm{P} \leq 0.001)$ also between the laser acupuncture group and the control group $(\mathrm{P} \leq 0.001)$.

However, the results of this clinical study are inconsistent with many published clinical trials. Recently, Tascioglu et al. [47] reported that LLLT has no effect on pain in patients with KOA by the dose of $3 \mathrm{~J}$. This failure in pain reduction may be due to the laser modality, dosages, site of points, and wavelength selection used in this trial. Yurtkuran et al. [35] conducted a clinical trial to inves-

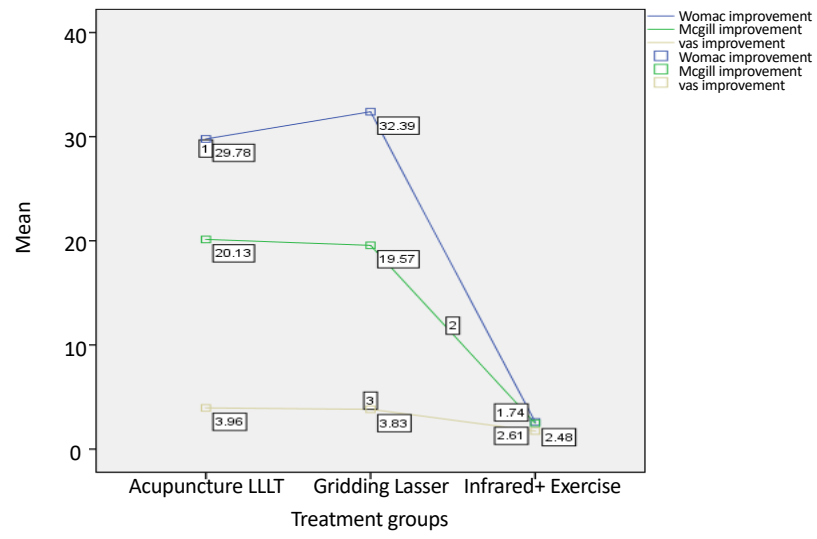

Figure 1. Levels of improvement for all outcome measures among the experimental groups 
tigate the effects of laser acupuncture in knee OA and compared it with placebo treatment. The acupuncture point of Sp9 was irradiated for $120 \mathrm{~s}(0.48 \mathrm{~J})$ treatment time per session.

The result showed an improvement of knee swelling as shown by better knee circumference measurement in the laser group compared to the placebo group. The results of our study are different from the study conducted by Yurtkuran et al. The variation may be due to lower laser doses. They used a dose that may be too low, in addition, they used just one acupuncture point. Yurtkuran et al. used a laser device with a power density of $10 \mathrm{~mW} /$. This power density may be very low to affect mast cell degranulation, which is important to stimulate the acupuncture point [47].

An early study by Bülow et al. [27] concluded that laser irradiation, with $830 \mathrm{~nm}$ wavelength and dosages of 1.5 to $4.5 \mathrm{~J}$, applied for 15 minutes with a total dosage of $22.5 \mathrm{~J}$ per session (distributed as an average of 2.5 J per point) failed to demonstrate substantial improvement in patients with the OA. This opposite result might be related to inappropriate dosages (very low) that were applied per point plus the unsuitable site of points that might not be appropriate for the treatment. These discrepancies may be attributed to variations in parameters of LLLT such as wavelength, number of points, power, energy density, the method of laser administration, duration of treatment, size of the exposure area, and method of laser administration.

All of these factors will affect the clinical and therapeutic outcomes of laser applications. However, our study results suggest that short-term LLLT improves pain, physical function, and activities in patients with KOA. Further studies may be required to investigate the effect of these different variables to confirm the difference in results. Al Rashoud et al. [34] conducted a clinical trial to evaluate the efficacy of LLLT on acupuncture points of knee joint combined with exercise. These researchers applied lower dosage and power density. Their results demonstrated that short-term application of the LLLT on specific acupuncture points along with exercises was effective to reduce pain and improve quality of life in patients with KOA [34].

The results of this study are similar to the result of $\mathrm{Fu}-$ kuda et al. who found a significant improvement in pain and function in the laser group (energy of $3.0 \mathrm{~J}$ per point) compared with placebo in all the assessments applied to the groups [48]. Similar results were found in clinical trials of Rayegani et al. [49] and Hegedus et al. [50]. They used Ga-Al-As laser with a dose of $6 \mathrm{~J}$ per point. The results show that LLLT reduces pain, joint stiffness, and disability in KOA.

The findings of this study agree with the results of Dwi R. Helianthi et al. [33] study that compared the effectiveness of active laser acupuncture with placebo in reducing pain intensity and improving functional outcome in older patients with KOA. A total of 62 patients with knee OA were treated by using a gallium aluminum arsenide laser device at 5 acupuncture points over the affected knee for 10 sessions. The researchers found that the active laser acupuncture is effective in reducing pain and improving functional ability.

The exact physiologic and therapeutic effects of LLLT on human soft tissues are, unfortunately, far from wellestablished or understood. There is a strong consensus in the scientific literature, however, that LLLT induces photobiomodulation effects through photochemical interactions between photons and healthy cells within and around the soft-tissue pathology [51].

Former research studies revealed that the LLLT application had a wide range of effects at molecular, cellular, and tissue levels. Besides, the specific modes of action may lead to various effects on different applications [51]. The strong evidence suggests that the LLLT affects mitochondria action [52], increases Adenosine Triphosphate (ATP) production [53], modulates Reactive Oxygen Species (ROS), and induces transcription factors within cell level [54].

Several transcription factors are regulated by changes in cellular redox state such as redox factor-1, dependent activator protein-1 (a heterodimer of c-Fos and c-Jun), nuclear factor kappa B, p53, activating transcription factor/cAMP-response element-binding protein, HypoxiaInducible Factor (HIF)-1, and HIF-like factor [54]. These transcription factors improve protein synthesis and trigger further effects, such as increased cell proliferation and migration (particularly in fibroblasts), modulation of cytokines, growth factors and inflammatory mediators, and increased tissue oxygenation [55].

Serra et al. [56] suggested that analgesic effects of laser acupuncture came from low-level laser effects to increase the peripheral release of opioids through migration of immune system cells, with local release of betaendorphin, which is antagonized by naloxone. When the histamine concentration increases, the nociceptors again become depolarized and rhythmic discharges may initiate. This may be the basic mechanism of laser acupunc- 
ture and suggests the important role of connective tissue in acupuncture.

Laser acupuncture and conventional laser have the same effect on reducing pain and increasing functional activity in patients with KOA and they are more effective when compared to the conventional treatment. Longer follow-up period is still necessary for further evaluation of the efficacy of the treatment modality.

\section{Ethical Considerations}

\section{Compliance with ethical guidelines}

All the procedures were carried out after the study was approved by the Scientific Board and Ethics Committee of the School of Rehabilitation, Tehran University of Medical Science (IR.TUMS.FNM.REC1397.161). All participants were informed about the procedures that would be carried out. The participants who agreed voluntarily to sign an identified consent form were considered for the study.

\section{Funding}

The present paper was extracted from the MSc. thesis of the first author, in International Campus, School of Rehabilitation, Tehran University of Medical Sciences.

\section{Authors' contributions}

Carrying out the literature search and review, data extracting, synthesizing results, preparing the initial draft, performing the statistical analysis, and submitting the manuscript: Ali Lafta Mezaal; Literature search and review, preparing the research framework, coordinating appraisal, Data critical appraisal, and preparing the manuscript revisions: Siamak Bashardoust Tajali; Search strategy and revisions of the manuscript: Gholamreza Olyaei, Shohreh Jalaie, Saddi Thweab Alwatifi; Statistical suggestions and analysis: Shohreh Jalaie; and Reading and approving the final article: All authors.

\section{Conflict of interest}

The authors declared no conflict of interest.

\section{References}

[1] Lawrence RC, Felson DT, Helmick CG, Arnold LM, Choi $\mathrm{H}$, Deyo RA, et al. Estimates of the prevalence of arthritis and other rheumatic conditions in the United States: Part II. Arthritis \& Rheumatology. 2008; 58(1):26-35. [DOI:10.1002/ art.23176] [PMID] [PMCID]
[2] Felson DT. Developments in the clinical understanding of Osteoarthritis. Arthritis Research \& Therapy. 2009; 11:203. [DOI:10.1186/ar2531] [PMID] [PMCID]

[3] Gupta S, Hawker G, Laporte A, Croxford R, Coyte P. The economic burden of disabling hip and Knee Osteoarthritis (OA) from the perspective of individuals living with this condition. Rheumatology. 2005; 44(12):1531-7. [DOI:10.1093/ rheumatology/kei049] [PMID]

[4] Wallace IJ, Worthington S, Felson DT, Jurmain RD, Wren $\mathrm{KT}$, Maijanen $\mathrm{H}$, et al. Knee osteoarthritis has doubled in prevalence since the mid- $20^{\text {th }}$ century. Proceedings of the National Academy of Sciences. 2017; 114(35):9332-6. [DOI: 10.1073/pnas.1703856114] [PMCID] [PMID]

[5] O'Sullivan SB, Schmitz TJ, Fulk G. Physical rehabilitation. Philadelphia: FA Davis; 2014.

[6] Ho SC, Woo J, Chan SS, Yuen Y, Sham A. Risk factors for falls in the Chinese elderly population. The Journals of Gerontology Series A. 1996; 51(5):M195-M8. [DOI:10.1093/ gerona/51A.5.M195] [PMID]

[7] Klippel Je. Primer on the rheumatic diseases. Berlin: Springer; 2011.

[8] Valdes AM, Spector TD. The contribution of genes to Osteoarthritis. Rheumatic Disease Clinics of North America. 2008; 34(3):581-603. [DOI:10.1016/j.rdc.2008.04.008] [PMID]

[9] Felson DT. Risk factors for Osteoarthritis: Understanding joint vulnerability. Clinical Orthopaedics and Related Research (1976-2007). 2004; (427 Suppl.):S16-S21. [PMID]

[10] American College of Rheumatology Subcommittee on Rheumatoid Arthritis G. Guidelines for the management of Rheumatoid Arthritis: 2002 Update. Arthritis \& Rheumatology. 2002; 46(2):328-46. [PMID]

[11] Hafez AR, Al-Johani AH, Zakaria AR, Al-Ahaideb A, Buragadda S, Melam GR, et al. Treatment of Knee Osteoarthritis in relation to hamstring and quadriceps strength. Journal of Physical Therapy Science. 2013; 25(11):1401-5. [DOI:10.1589/ jpts.25.1401] [PMID] [PMCID]

[12] Welch V, Brosseau L, Casimiro L, Judd M, Shea B, Tugwel $\mathrm{P}$, et al. Thermotherapy for treating Rheumatoid Arthritis. Hoboken: Cochrane Database of Systematic Reviews; 2002.

[13] Oosterveld FGJ, Rasker JJ. Effects of local heat and cold treatment on surface and articular temperature of arthritic knees. Arthritis \& Rheumatism. 1994; 37(11):1578-82 [DOI:10.1002/art.1780371104]

[14] Draper DO, Klyve D, Ortiz R, Best TM. Effect of low-intensity long-duration ultrasound on the symptomatic relief of Knee Osteoarthritis: A randomized, placebo-controlled double-blind study. Journal of Orthopaedic Surgery and Research. 2018; 13(1):257. [DOI:10.1186/s13018-018-0965-0] [PMID] [PMCID]

[15] Atamaz FC, Durmaz B, Baydar M, Demircioglu OY, Iyiyapici A, Kuran B, et al. Comparison of the efficacy of transcutaneous electrical nerve stimulation, interferential currents, and shortwave diathermy in Knee Osteoarthritis: A doubleblind, randomized, controlled, multicenter study. Archives of Physical Medicine and Rehabilitation. 2012; 93(5):748-56 [DOI:10.1016/j.apmr.2011.11.037] [PMID] 
[16] Brosseau L, Judd M, Marchand S, Robinson V, Tugwell P, Wells G, et al. Transcutaneous Electrical Nerve Stimulation (TENS) for the treatment of Rheumatoid Arthritis in the hand. Cochrane Database of Systematic Reviews. 2003; 3(2):CD004377. [DOI:10.1002/14651858.CD004377]

[17] Sharma L, Song J, Felson DT, Cahue S, Shamiyeh E, Dunlop $\mathrm{DD}$. The role of knee alignment in disease progression and functional decline in Knee Osteoarthritis. JAMA. 2001; 286(2):188-95. [DOI:10.1001/jama.286.2.188] [PMID]

[18] Herrington L, Payton CJ. Effects of corrective taping of the patella on patients with patellofemoral pain. Physiotherapy. 1997; 83(11):566-72. [DOI:10.1016/S0031-9406(05)65961-5]

[19] Tang L, Jia P, Zhao L, Kang D, Luo Y, Liu J, et al. Acupuncture treatment for Knee Osteoarthritis with sensitive points: Protocol for a multicentre randomised controlled trial. BMJ Open. 2018; 8(10):e23838. [DOI:10.1136/bmjopen-2018-023838] [PMID] [PMCID]

[20] Ganji R, Pakniat A, Armat MR, Tabatabaeichehr M, Mortazavi $H$. The effect of self-management educational program on pain intensity in elderly patients with Knee Osteoarthritis: A randomized clinical trial. Open Access Macedonian Journal of Medical Sciences. 2018; 6(6):1062-6. [DOI:10.3889/oamjms.2018.225]

[21] Brosseau L, Wells G, Marchand S, Gaboury I, Stokes B, Morin M, et al. Randomized controlled trial on Low Level Laser Therapy (LLLT) in the treatment of Osteoarthritis (OA) of the hand. Lasers in Surgery and Medicine. 2005;36(3):210-9. [DOI:10.1002/lsm.20137] [PMID]

[22] Farivar S, Malekshahabi T, Shiari R. Biological effects of low level laser therapy. Journal of Lasers in Medical Sciences. 2014; 5(2):58-62. [PMID] [PMCID]

[23] Rayegani SM, Raeissadat SA, Heidari S, Moradi-Joo M. Safety and effectiveness of Low-Level Laser Therapy in patients with Knee Osteoarthritis: A systematic review and meta-analysis. Journal of Lasers in Medical Sciences. 2017; 8(Suppl. 1):S12-9. [DOI:10.15171/jlms.2017.s3] [PMID] [PMCID]

[24] Brosseau L, Welch V, Wells G, DeBie R, Gam A, Harman $\mathrm{K}$, et al. Low Level Laser Therapy (Classes I, II and III) for treating Osteoarthritis. Cochrane Library: Cochrane Reviews. 2004(3):Cd002046. [DOI:10.1002/14651858.CD002046.pub2]

[25] Hawker GA, Mian S, Kendzerska T, French M. Measures of adult pain: Visual Analog Scale for pain (VAS pain), Numeric Rating Scale for pain (NRS pain), McGill Pain Questionnaire (MPQ), Short-Form McGill Pain Questionnaire (SF-MPQ), Chronic Pain Grade Scale (CPGS), Short Form-36 Bodily Pain Scale (SF-36 BPS), and measure of Intermittent and Constant Osteoarthritis Pain (ICOAP). Arthritis Care \& Research. 2011; 63(S11):S240-S52. [DOI:10.1002/acr.20543] [PMID]

[26] Tascioglu F, Armagan O, Tabak Y, Corapci I, Oner C. Low power laser treatment in patients with Knee Osteoarthritis. Swiss Medical Weekly. 2004; 134(17-18):254-8. [PMID]

[27] Bülow P, Jensen H, Danneskiold-Samsøe B. Low power Ga-Al-As laser treatment of painful Osteoarthritis of the knee. A double-blind placebo-controlled study. Scandinavian Journal of Rehabilitation Medicine. 1994; 26(3):155-9. [PMID]

[28] Huang Z, Ma J, Chen J, Shen B, Pei F, Kraus VB. The effectiveness of Low-Level Laser Therapy for nonspecific chronic low back pain: A systematic review and meta-analysis. Ar- thritis Research \& Therapy. 2015; 17:360. [DOI:10.1186/ s13075-015-0882-0] [PMID] [PMCID]

[29] Hakguder A, Birtane M, Gurcan S, Kokino S, Turan FN. Efficacy of Low Level Laser Therapy in myofascial pain syndrome: An algometric and thermographic evaluation. Lasers in Surgery and Medicine. 2003; 33(5):339-43. [DOI:10.1002/ 1sm.10241] [PMID]

[30] Laakso EL, Richardson C, Cramond T. Pain scores and side effects in response to Low Level Laser Therapy (LLLT) for myofascial trigger points. Laser Therapy. 1997; 9(2):67-72. [DOI:10.5978/islsm.9.67]

[31] Kreisel V, Weber M. A practical handbook: Laser acupuncture- successful treatment concepts. Vancouver: Eastern Currents Distributing; 2012.

[32] Hinman RS, McCrory P, Pirotta M, Relf I, Forbes A Crossley KM, et al. Acupuncture for chronic knee pain: A randomized clinical trial. JAMA. 2014; 312(13):1313-22. [DOI:10.1001/jama.2014.12660] [PMID]

[33] Helianthi DR, Simadibrata C, Srilestari A, Wahyudi ER Hidayat R. Pain reduction after laser acupuncture treatment in geriatric patients with Knee Osteoarthritis: A randomized controlled trial. Acta Medica Indonesiana. 2016; 48(2):114-21. [PMID]

[34] Al Rashoud A, Abboud R, Wang W, Wigderowitz C. Efficacy of Low-Level Laser Therapy applied at acupuncture points in Knee Osteoarthritis: A randomised double-blind comparative trial. Physiotherapy. 2014; 100(3):242-8. [DOI:10.1016/j. physio.2013.09.007] [PMID]

[35] Yurtkuran M, Alp A, Konur S, Özçakir S, Bingol U. Laser acupuncture in Knee Osteoarthritis: A double-blind, randomized controlled study. Photomedicine and Laser Therapy. 2007; 25(1):14-20. [DOI:10.1089/pho.2006.1093] [PMID]

[36] Shen X, Zhao L, Ding G, Tan M, Gao J, Wang L, et al. Effect of combined laser acupuncture on Knee Osteoarthritis: A pilot study. Lasers in Medical Science. 2009; 24(2):129-36. [DOI:10.1007/s10103-007-0536-9] [PMID]

[37] Kellgren J, Lawrence JS. Radiological assessment of osteoarthrosis. Annals of the Rheumatic Diseases. 1957; 16(4):494502. [DOI:10.1136/ard.22.4.237] [PMID] [PMCID]

[38] Kheshie AR, Alayat MSM, Ali MME. High-intensity versus Low-Level Laser Therapy in the treatment of patients with Knee Osteoarthritis: A randomized controlled trial. Lasers in Medical Science. 2014; 29(4):1371-6. [DOI:10.1007/s10103-0141529-0] [PMID]

[39] Chow SC. Sample size calculations in clinical research. Didcot, England: Taylor \& Francis Group; 2008

[40] White A, Cummings M, Filshie J. An introduction to western medical acupuncture. Amsterdam: Elsevier; 2008.

[41] Anwer S, Alghadir A. Effect of isometric quadriceps exercise on muscle strength, pain, and function in patients with Knee Osteoarthritis: A randomized controlled study. Journal of Physical Therapy Science. 2014; 26(5):745-8. [DOI:10.1589/ jpts.26.745] [PMID] [PMCID]

[42] Terkawi AS, Tsang S, Abolkhair A, Alsharif M, Alswiti M, Alsadoun A, et al. Development and validation of Arabic version of the short-form McGill Pain Questionnaire. Saudi Jour- 
nal of Anaesthesia. 2017; 11(Suppl. 1):S2-S10. [DOI:10.4103/ sja.SJA_130_17]

[43] Bellamy N, Buchanan WW, Goldsmith CH, Campbell J, Stitt LW. Validation study of WOMAC: A health status instrument for measuring clinically important patient relevant outcomes to antirheumatic drug therapy in patients with Osteoarthritis of the hip or knee. The Journal of Rheumatology. 1988; 15(12):1833-40. [PMID]

[44] Guermazi M, Poiraudeau S, Yahia M, Mezganni M, Fermanian J, Elleuch $\mathrm{MH}$, et al. Translation, adaptation and validation of the Western Ontario and McMaster Universities Osteoarthritis index (WOMAC) for an Arab population: The $\mathrm{S}$ fax modified WOMAC. Osteoarthritis and Cartilage. 2004; 12(6):459-68. [DOI:10.1016/j.joca.2004.02.006] [PMID]

[45] Gerhardt JJ, Rondinelli RD. Goniometric techniques for range-of-motion assessment. Physical Medicine and Rehabilitation Clinics. 2001; 12(3):507-28. [DOI:10.1016/S10479651(18)30047-0]

[46] World Association for Laser Therapy. Recommended treatment doses for Low Level Laser Therapy [Internet]. 2010 [Updated 12 April 2010]. Available from: http:/ / waltza. co.za/wp-content/uploads/2012/08/Dose_table_904nm_ for_Low_Level_Laser_Therapy_WALT-2010.pdf

[47] Schikora D. Laserneedle acupuncture: A critical review and recent results. Medical Acupuncture. 2008; 20(1):37-42. [DOI:10.1089/acu.2007.0606]

[48] Fukuda VO, Fukuda TY, Guimarães M, Shiwa S, de Lima BDC, Martins RÁBL, et al. Short-term efficacy of Low-Level Laser Therapy in patients with Knee Osteoarthritis: a randomized placebo-controlled, double-blind clinical trial. Revista Brasileira de Ortopedia (English Edition). 2011; 46(5):526-33. [DOI:10.1590/S0102-36162011000500008]

[49] Rayegani SM, Bahrami MH, Elyaspour D, Saeidi M, Sanjari H. Therapeutic effects of Low Level Laser Therapy (LLLT) in Knee Osteoarthritis, compared to therapeutic ultrasound. Journal of Lasers in Medical Sciences. 2012; 3(2):71-4 [DOI:10.22037/2010.v3i2.2830]

[50] Hegedús B, Viharos L, Gervain M, Gálfi M. The effect of low-level laser in Knee Osteoarthritis: A double-blind, randomized, placebo-controlled trial. Photomedicine and Laser Surgery. 2009; 27(4):577-84. [DOI:10.1089/pho.2008.2297] [PMID] [PMCID]

[51] Chung H, Dai T, Sharma SK, Huang YY, Carroll JD, Hamblin MR. The nuts and bolts of low-level laser (light) therapy. Annals of Biomedical Engineering. 2012; 40(2):516-33. [DOI:10.1007/s10439-011-0454-7] [PMID] [PMCID]

[52] Greco M, Guida G, Perlino E, Marra E, Quagliariello E. Increase in RNA and protein synthesis by mitochondria irradiated with helium-neon laser. Biochemical and Biophysical Research Communications. 1989; 163(3):1428-34. [DOI:10.1016/0006-291X(89)91138-8]

[53] Karu T. Primary and secondary mechanisms of action of visible to near-IR radiation on cells. Journal of Photochemistry and Photobiology B: Biology. 1999; 49(1):1-17. [DOI:10.1016/ S1011-1344(98)00219-X]

[54] Chen AC, Arany PR, Huang YY, Tomkinson EM, Sharma SK, Kharkwal GB, et al. Low-Level Laser Therapy activates NF-kB via generation of reactive oxygen species in mouse embryonic fibroblasts. PLOS One. 2011; 6(7):e22453. [DOI:10.1371/journal.pone.0022453]

[55] Karu TI, Kolyakov S. Exact action spectra for cellular responses relevant to phototherapy. Photomedicine and Laser Therapy. 2005; 23(4):355-61. [DOI:10.1089/pho.2005.23.355] [PMID]

[56] Serra AP, Ashmawi HA. Influence of naloxone and methysergide on the analgesic effects of low-level laser in an experimental pain model. Revista Brasileira De Anestesiologia. 2010; 60(3):302-10. [DOI:10.1016/S0034-7094(10)70037-4] 


\section{Appendices}

1. Numeric Rating Scale pain

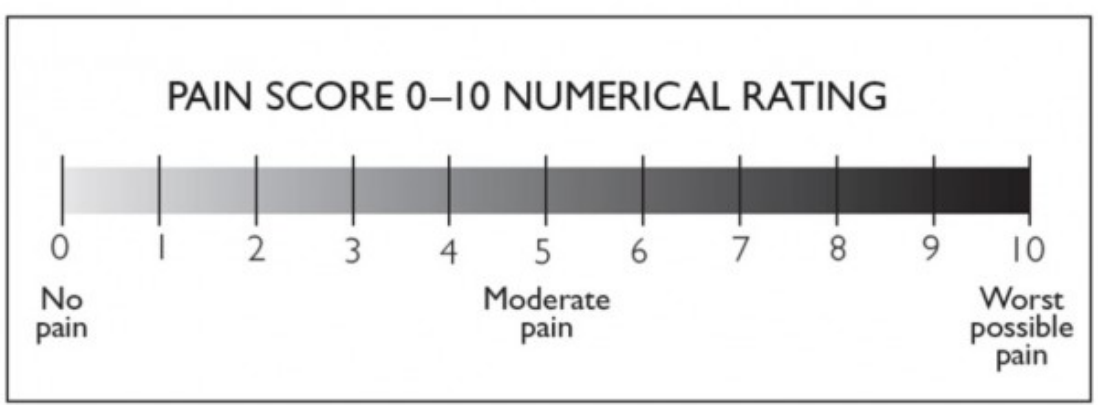

2. Short Form of McGill Pain Questionnaire (Arabic version)

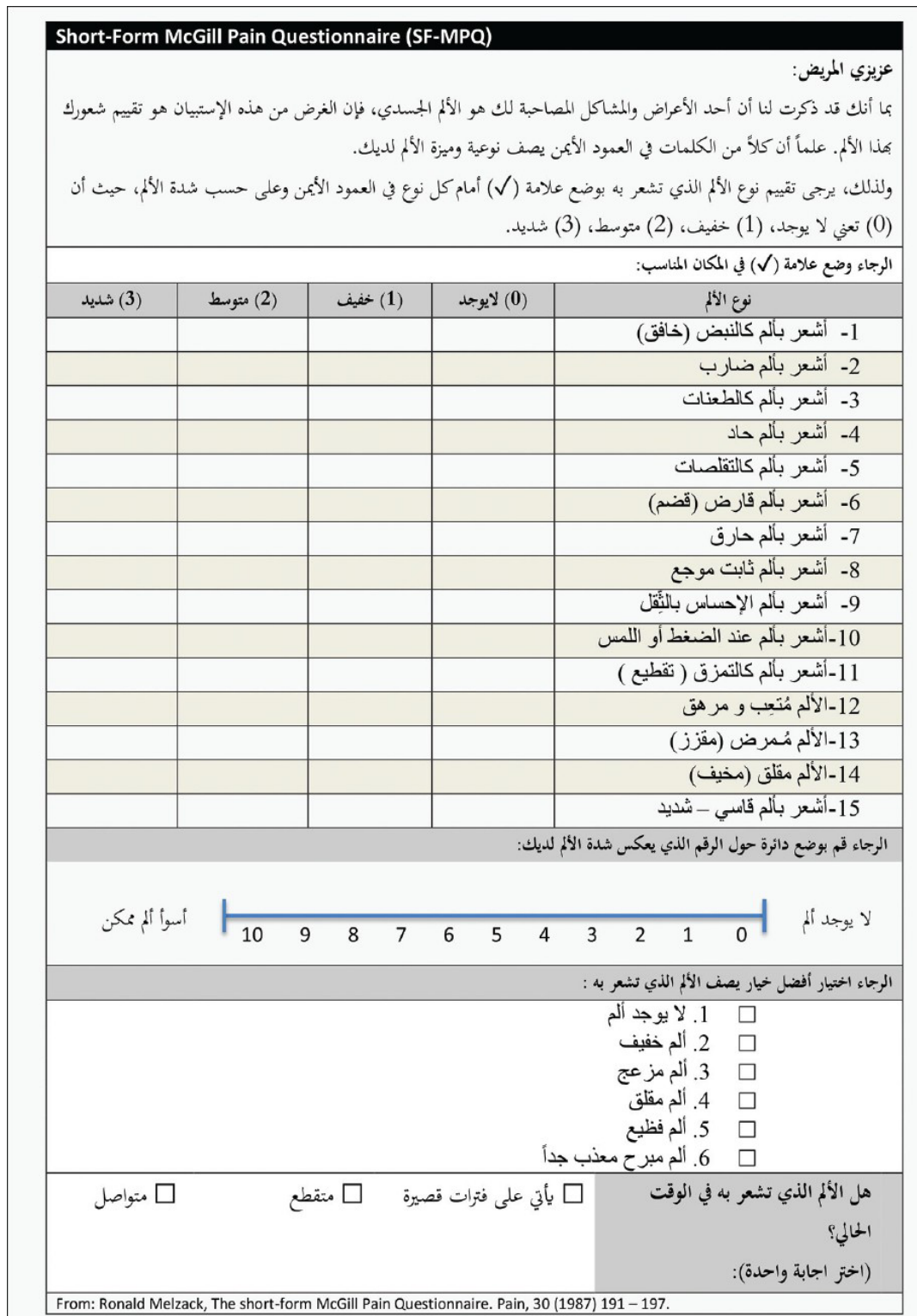


3. The Western Ontario and McMaster Universities Arthritis Index (WOMAC) (Arabic version)

\section{WOMAC index}

0 : not any

1 : a little

2 : moderate

3 : important

4 : very important - extreme

\section{P Subscale:}

How much pain do you have:

1: walking on flat surface

2: going up or down stairs

3: at night while in bed

4: sitting or lying

5: standing upright

\section{S Subscale : :}

how severe is your stiffiness

1:After first wakening in the morning

2:After sitting lying or resting later in the day

\section{PF subscale:}

What degree of difficulty do you have

1: descending stairs

2: ascending stairs

3: rising from sitting

4: standing

5 : bending to floor

6: walking on flat

7: getting in / out of car

8: going shopping

9: putting on socks/stockings

10: rising from bed

11: taking off socks / stockings

12: lying in bed

13: getting in / off bath

14 : sitting

15: getting on / off toilet

16: heavy domestic duties

17 : light domestic duties

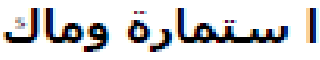

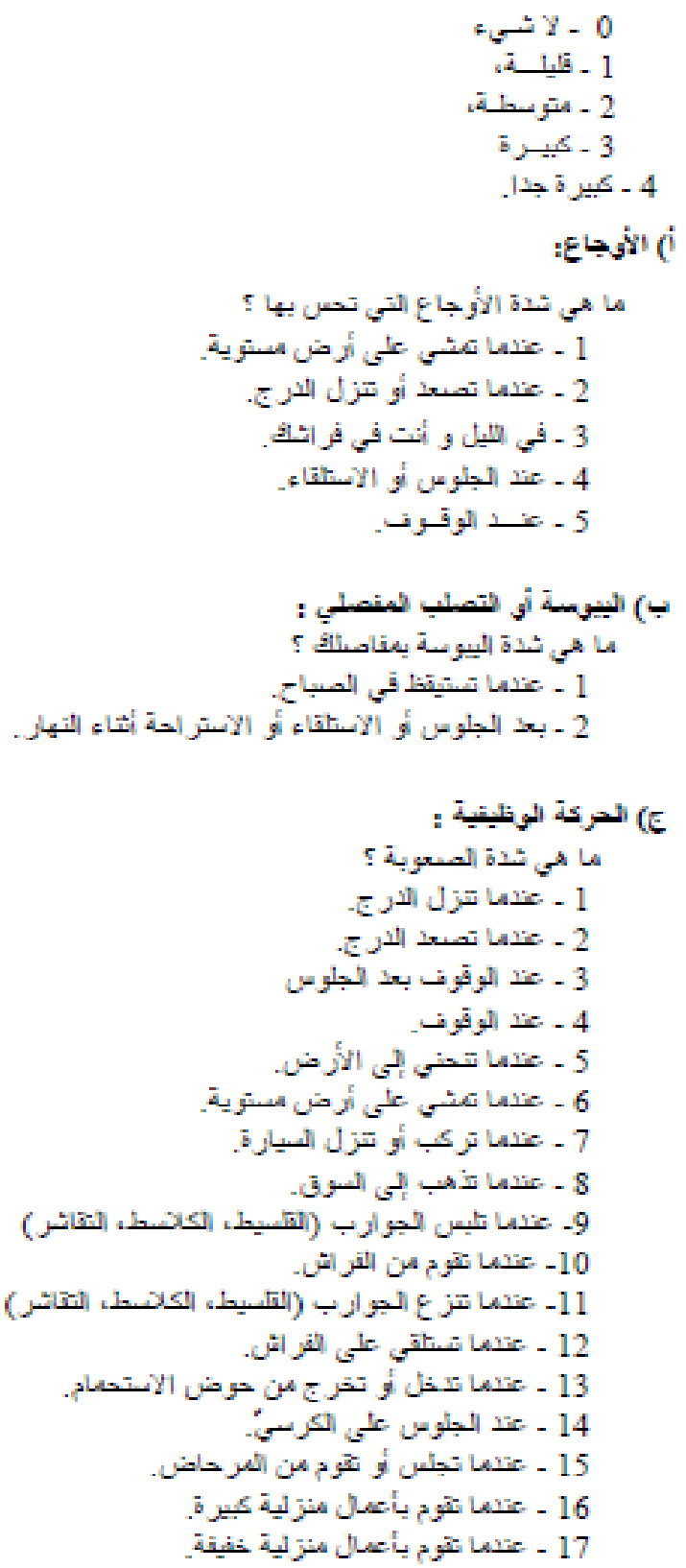

